\title{
Nipple discharge: Follow-up in operated versus non- operated patients - A single center experience
}

\author{
Diana M Røpcke*, Susanne Bokmand and Henrik Flyger \\ Department of Breast Surgery, Herlev Hospital, Copenhagen University Hospital, Denmark
}

\begin{abstract}
Introduction: Patients with nipple discharge are often treated surgically and pose a diagnostic and therapeutic challenge. The objective of the present study was to investigate if clinical predictors of underlying malignancy could be identified.

Material and methods: We retrospectively identified 400 patients with nipple discharge as primary complaint at referral in our institution from 2007 to 2015 . Two hundred patients were surgically treated, and two hundred were observed. Patient charts, national health registries, radiology findings and pathology findings were evaluated. The two groups were compared, and the patients with invasive cancer / carcinoma in situ (CIS) was characterized.

Results: In the operated group, patients were significantly older, and more patients had bloody discharge $(p<0.001)$. In the operated group, invasive cancer was found in $2 \%$, and CIS was found in $9 \%$ of cases. No radiologic finding had indicated this preoperatively. Recurrent bloody nipple discharge was seen more frequently in the invasive cancer group. During follow-up, one case of invasive cancer emerged in each group. A history of previous breast cancer significantly increased the risk of an underlying invasive cancer in nipple discharge patients $(p<0.05)$

Conclusion: Current clinical stratification identifies patients with pathological nipple discharge requiring surgery, but over-treatment is a concern. According to existing literature, and partially supported by the current study findings, all women aged 50 years or more presenting with recurrent, bloody nipple discharge should be offered duct excision, which remains the diagnostic gold standard, especially in case of a medical history with previous breast cancer.
\end{abstract}

\section{Introduction}

Nipple discharge (Figure 1) is a common symptom in patients referred to breast cancer clinics and accounts for $2-5 \%$ of all referrals [1]. It causes considerable anxiety, although usually physiologic or caused by benign aetiologies [2]. Nevertheless, nipple discharge has been reported in the literature to be the presenting symptom in breast cancer in up to $15 \%$ of cases with great variation $(5-15 \%)[3,4]$.

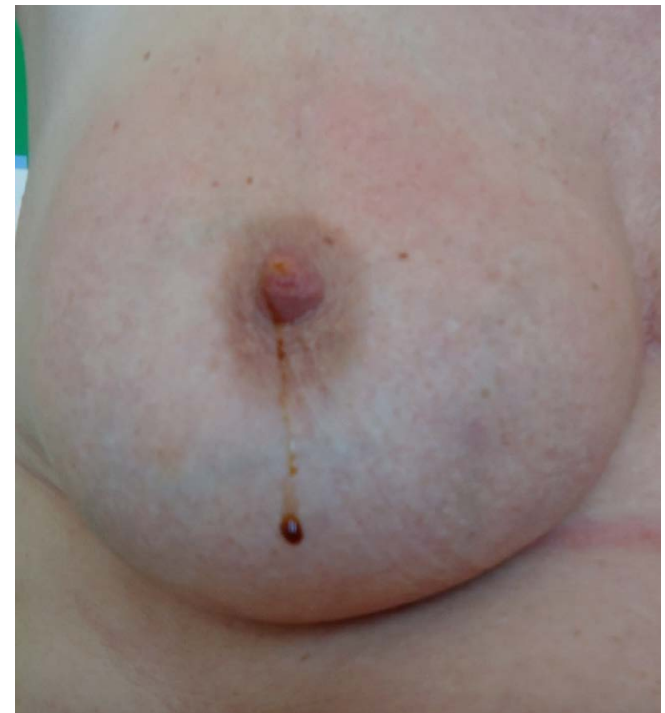

Figure 1. Nipple discharge. Clinical photo showing bloody/serosanguineous nipple discharge from the right breast
Typically, physiologic discharge is bilateral with discharge from more than one duct. Usually, physiological discharge is not bloody, but any colour can be seen (clear, grey, yellow, green or brown). Discharge can be stimulated by manipulation of the breast or nipple $[5,6]$. Physiologic milky discharge during pregnancy or in breastfeeding women is called galactorrhoea. In other settings, galactorrhoea can be caused by hyperprolactinemia or thyroid disease, making endocrinopathy plausible. Medications inhibiting dopamine can also cause discharge [7].

Pathologic discharge is typically spontaneous, unilateral, serous/ clear/bloody [8], or seen in association with a breast mass [9]. The most common cause of pathologic discharge is benign papillomas, which are found in $57 \%$ of pathologic discharge patients [10]. Papillomas typically produce bloody or clear discharge, and may be associated with low grade carcinomas or atypical cells [11]. The second most common cause is duct ectasia seen in $33 \%$ of patients [10], while malignancy (typically ductal carcinoma in situ) is found in $5-15 \%$ of pathologic discharge patients $[3,12,13]$. The vast majority of breast cancers are invasive ductal carcinomas, while the remaining are lobular invasive carcinomas or other rare invasive cancers (e.g. Phylloides tumours). Carcinoma in situ (CIS) is not invasive (respects the basal membrane)

*Correspondence to: Diana M Røpcke, Department of Breast Surgery F, Herlev Ringvej 75, 18th floor, 2730 Herlev, Denmark, Tel: 45-386-825-66, Fax: 45-386825-00, E-mail: dmr@dadlnet.dk

Key words: Nipple discharge, follow-up, duct excision, breast cancer

Received: June 09, 2018; Accepted: June 25, 2018; Published: June 30, 2018 
and shows the same pathological pattern, with a predominantly ductal origin. CIS has an inherent risk of turning into invasive cancers [13].

The evaluation and management of nipple discharge is diverse and confusing between departments and countries [14]. The primary focus of the evaluation of each patient is to distinguish between physiologic and pathologic nipple discharge in order to save women the risks and discomfort associated with an unnecessary operation, while sufficiently identifying and treating women in risk of invasive cancer.

Standard examination of patients with nipple discharge includes medical history, physical examination, and radiographic examination (mammography and/or ultrasonography) if findings and symptoms raise an indication [15]. Ductography and ductoscopy have been used in cases with an actively discharging duct, but has not proven to be reliable to distinguish between benign and malignant causes of discharge $[16,17]$. Magnetic resonance imaging (MRI) is able to identify occult pathologies and may have a future role in the evaluation of patients, but the current role of MRI as a diagnostic tool in nipple discharge patients is not yet established [18].

The challenge for surgeons is to identify patients with pathological discharge and to offer this group surgical excision, while all patients with physiological discharge can avoid surgery and the risk associated with surgery.

In this study, we reviewed 400 cases of patients with nipple discharge as a single symptom referred to our institution from 2007 until 2015 and compared the surgically treated group with the group treated conservatively (observation and follow-up). Furthermore, the patients diagnosed with cancer were characterized.

The aim of the present study was to identify clinical characteristics or preoperative examinations which can be used to identify malignancy as the underlying cause of nipple discharge, thereby facilitating patienttailored treatment. Furthermore, current patient selection is evaluated.

\section{Material and methods}

Four hundred consecutive female patients were identified by searching the department clinical database for diagnosis code DN 64.52 (nipple discharge, not milk). Patients were not randomized. Two hundred consecutive women receiving an operation, and two hundred consecutive women treated conservatively for this diagnosis, were found. These patients were referred to our department from March 2007 to May 2015 with nipple discharge as a single symptom. All patients were evaluated retrospectively based on chart review, radiographic findings and pathologic findings at referral. Dietary intake data was not available.

In the study, we controlled for the following factors: Age at presentation, previous breast cancer, colour of discharge, imaging findings, and side of discharge. Patient review was performed by a single observer, and the study was approved by the Danish Data Protection Agency and by institutional health authorities. At referral, all patients were evaluated according to the national guidelines, which included a thorough patient history, triple assessment diagnostics (physical examination, mammography, and ultrasound), and pathological examination in cases where a biopsy was taken. Discharge was stratified into clear, multi-coloured or bloody as described in the patient file by the treating surgeon. Hemoccult testing was not routinely performed because of questionable sensitivity [19].

Ductography / ductoscopy or MRI were not used. Patients were treated and operated by 9 different experienced and certified breast surgeons. Patients with nipple discharge as a first-time single symptom were scheduled for follow-up within 4-6 months, while surgery was offered in case of any radiographic finding, recurrent nipple discharge, or on patient request. Patients received either a single duct excision (minor surgery) guided by injection of methylene blue in the affected duct or using a peri-areolar incision with rising of the areola flap and removal of all ducts identified from the dermal level to the end of visible ductal tissue (major surgery).

Invasive cancer or carcinoma in situ (CIS) in the follow up period were found searching these two diagnoses in the Danish Database of Pathology, which is a complete national registry with decades of complete data sets coupled to personal registration numbers. Invasive cancer / CIS cases were diagnosed through the national breast cancer screening program, in which all women above the age of 50 years are included.

\section{Statistics}

Data was collected using Excel (Microsoft Office). All data were analysed using SPSS statistics (version 22, IBM), and the significance level was defined as $p<0.05$. Data are presented as medians with a range, or with $95 \%$ confidence intervals $(95 \% \mathrm{CI})$.

Normal distribution of data was tested with QQ-plots. Data showing normal distribution was analysed using chi square test for comparison of two independent groups. When sample size was small, Fisher's exact test was used. The Mann-Whitney U-test was chosen for data, where normal distribution was not found. A multivariate analysis was performed in order to identify factors independently associated with invasive cancer.

\section{Results}

Median follow up time was 38 months in the operated group, and 51 months in the group treated conservatively $(p<0.001)$. The age range was from 18 to 95 years, and patients were ethnic Caucasians. Preoperatively, cancer was not suspected in any of the patients since no suspicious radiographic findings or palpable masses were treated with surgery for nipple discharge, owing to the Danish guidelines where any suspicion of cancer leads the patient into specific cancer programs.

Patients in the operated group were significantly older, showed significantly more frequently bloody discharge and less frequently multi-coloured discharge, compared to the non-operated patients (Table 1). No differences were found regarding previous breast cancer, side, or radiographic findings between groups (Table 1).

One third of operated patients had a single duct excision (minor surgery), while two third of patients were operated using a periareolar incision (major surgery). As seen in Table 2, 11\% of operated patients had minor complications such as infection needing antibiotic treatment, partial areolar necrosis treated conservatively, and fistula formation ( 2 patients), which healed on antibiotics alone without surgical intervention. Interestingly, pathology showed ductectasia (47.5\%) and papilloma (39.5\%) being the most common finding, while ductal carcinoma in situ (CIS) was present in $8 \%$ of cases, and invasive cancer was present in $2.5 \%$ (Table 2). All invasive cancers were ductal carcinomas.

Looking at operated patients with invasive cancer or CIS, no difference was found in this group compared to the no-cancer patients regarding age, type of discharge, or radiographic findings (Table 3). All invasive cancer or CIS patients had normal radiographic findings, and 
Table 1. Patient characteristics and comparison between operated vs. non-operated patients

\begin{tabular}{|c|c|c|c|c|c|}
\hline \multirow{2}{*}{\multicolumn{2}{|c|}{ Patient characteristics }} & \multirow[t]{2}{*}{$\begin{array}{c}\text { Operation } \\
\mathrm{n}=200\end{array}$} & \multirow[t]{2}{*}{$\begin{array}{l}\text { Conservative treatment } \\
\mathrm{n}=200\end{array}$} & \multicolumn{2}{|c|}{ Operated vs. conservative treatment } \\
\hline & & & & OR $(95 \%$ CI $)$ & $p$ value \\
\hline \multicolumn{2}{|l|}{$\begin{array}{l}\text { Age in years } \\
\text { (median (range)) }\end{array}$} & $59(29-95)$ & $48(18-92)$ & NA & $<0.001$ \\
\hline \multicolumn{2}{|c|}{ Age over 50 (number (\%)) } & $141(70.5 \%)$ & $81(40.5 \%)$ & $3.51(2.31 ; 5.31)$ & $<0.001$ \\
\hline \multicolumn{2}{|c|}{ Observation time in months ${ }^{1)}$ (median (range)) } & $37.5(8-90)$ & $51(15-103)$ & NA & $<0.001$ \\
\hline \multicolumn{2}{|c|}{ Previous breast cancer (number (\%)) } & $6(3.0 \%)$ & $3(1.5 \%)$ & $2.03(0.50 ; 8.23)$ & 0.50 \\
\hline \multicolumn{6}{|c|}{ Discharge characteristics (number (\%)) } \\
\hline \multicolumn{2}{|l|}{ Bloody } & $142(71 \%)$ & $92(46 \%)$ & $2.87(1.90 ; 4.34)$ & $<0.001$ \\
\hline & Several times & $34(17 \%)$ & $9(4.5 \%)$ & $2.90(1.32 ; 6.38)$ & 0.006 \\
\hline Clear & & $38(19 \%)$ & $25(12.5 \%)$ & $1.64(0.94 ; 2.84)$ & 0.076 \\
\hline Multicoloured & & $20(10 \%)$ & $83(41.5 \%)$ & $0.16(0.09 ; 0.27)$ & $<0.001$ \\
\hline \multicolumn{2}{|c|}{ Right sided discharge (number (\%)) } & $103(51.5 \%)$ & $81(40.5 \%)$ & $1.56(1.05 ; 2.31)$ & 0.028 \\
\hline \multicolumn{6}{|c|}{ Breast imaging (number (\%)) } \\
\hline Normal & & $181(90.5 \%)$ & $179(89 \%)$ & $1.11(0.58 ; 2.15)$ & 0.7 \\
\hline Micro calcifications & & $2(1 \%)$ & $1(0.5 \%)$ & $2.01(0.18 ; 22.34)$ & 0.5 \\
\hline Duct ectasia & & $8(4 \%)$ & $12(6 \%)$ & $0.65(0.26 ; 1.63)$ & 0.4 \\
\hline Other & & $9(4.5 \%)$ & $8(4.0 \%)$ & $1.13(0.43 ; 2.99)$ & 0.8 \\
\hline
\end{tabular}

${ }^{1}$ Time after operation in the operated group and after diagnosis in the non-operated group.

Table 2. Operation type, pathology findings and complications

\begin{tabular}{|l|l|}
\hline Operation type & Outcome (n= 200) \\
\hline Operation & \\
\hline Minor surgery & $72(36 \%)$ \\
\hline Major surgery & $128(64 \%)$ \\
\hline Pathology & $95(47.5 \%)$ \\
\hline Duct ectasia & $79(39.5 \%)$ \\
\hline Papilloma & $16(8 \%)$ \\
\hline Carcinoma in situ & $5(2.5 \%)$ \\
\hline Cancer & $5(2 \%)$ \\
\hline Other & \\
\hline Complications & $178(89 \%)$ \\
\hline None & $22(11 \%)$ \\
\hline Minor & 0 \\
\hline Severe & \\
\hline
\end{tabular}

Minor surgery: single duct excision guided by methylene blue injection. Major surgery: excision of a lump of retroareolar tissue including the affected duct. Other pathology: fibrosis or infection. Minor complications: infection, small skin necrosis, and fistula formation treated conservatively.

Table 3. Characteristics of patients with cancer or carcinoma in situ (CIS) found by operation and following pathology

\begin{tabular}{|c|c|c|c|c|c|}
\hline Number of patients $(\%)$ & $\begin{array}{l}\text { Cancer } \\
(\mathrm{n}=5)\end{array}$ & $\underset{(n=16)}{\text { CIS }}$ & $\begin{array}{c}\text { Cancer }_{\text {total }}(\text { Cancer + CIS }) \\
(\mathrm{n}=21)\end{array}$ & $\begin{array}{c}\text { No cancer (operated) } \\
(\mathrm{n}=179)\end{array}$ & $\begin{array}{c}\text { Cancer }_{\text {total }} \text { vs. no cancer } \\
\text { OR }(95 \% \mathrm{CI})\end{array}$ \\
\hline Age over 50 & $4(80 \%)$ & $13(81.3 \%)$ & $17(80.9 \%)$ & $124(69.2 \%)$ & $1.88(0.60-5.86)$ \\
\hline Previous breast cancer & $1(20 \%)$ & $2(12.5 \%)$ & $3(14.2 \%)$ & $3(1.67 \%)$ & $9.78(1.83-52.0) *$ \\
\hline $\begin{array}{l}\text { Discharge } \\
\text { Clear } \\
\text { Multi-coloured } \\
\text { Bloody } \\
\text { - Once } \\
\text { - Several times }\end{array}$ & $\begin{array}{c}2(40 \%) \\
0 \\
3(60 \%) \\
2 \\
1\end{array}$ & $\begin{array}{c}3(18.8 \%) \\
1(6.3 \%) \\
12(75 \%) \\
8 \\
4\end{array}$ & $\begin{array}{c}5(23.8 \%) \\
1(4.8 \%) \\
15(71.4 \%) \\
10(47.6 \%) \\
5(23.8 \%)\end{array}$ & $\begin{array}{c}33(18.4 \%) \\
19(10.6 \%) \\
127(70.9 \%) \\
98(54.7 \%) \\
29(16.2 \%)\end{array}$ & $\begin{array}{r}1.38(0.47-4.0) \\
0.42(0.05-3.31) \\
1.02(0.37-2.78)\end{array}$ \\
\hline $\begin{array}{l}\text { Breast imaging } \\
\text { Normal } \\
\text { Ductectasia } \\
\text { Micro calcifications } \\
\text { Other }\end{array}$ & $\begin{array}{c}5(100 \%) \\
0 \\
0 \\
0\end{array}$ & $\begin{array}{c}16(100 \%) \\
0 \\
0 \\
0\end{array}$ & $\begin{array}{c}21(100 \%) \\
0 \\
0 \\
0\end{array}$ & $\begin{array}{c}160(89.4 \%) \\
8(4.4 \%) \\
2(1.1 \%) \\
9(5.0 \%)\end{array}$ & \\
\hline
\end{tabular}

Other breast imaging: fibrosis, infection. *: significant difference.

malignancy was not suspected prior to surgery in any of these patients. In the invasive cancer and CIS group, significantly more patients had a history of previous breast cancer, compared to the no-cancer group $(\mathrm{OR}=9.78$ (95\% CI: 1.83-52.0) (Table 3). The previous breast cancer was in the same breast in $78 \%$ of cases and the time from the first cancer was 2-4 years. In the CIS group, $44 \%$ of cases were Van Nuys group 1 , $17 \%$ were group 2 , and $22 \%$ were group 3 . Regarding invasive cancer,
$40 \%$ were grade $1,40 \%$ grade 2 , and $20 \%$ grade 3 . All were oestrogen receptor positive, and $60 \%$ were HER2 positive.

In the observation period from referral to end of follow-up, one patient in each group developed breast cancer in the operated breast (4 years after surgery, and 2 years after diagnosis, respectively). Both invasive cancers were in the peripheral part of the breast. Both were 
oestrogen receptor positive and HER2 negative, grade 1-2. One case of CIS (Van Nuys group 2) was found in the conservatively treated group one year after diagnosis (Table 4).

In the operated group, 142 patients presented with bloody discharge, while 58 patients showed non-bloody discharge. No differences were found between these two groups regarding age above 50 years or previous breast cancer prevalence, respectively ( $p>0.05$ in both cases) (Table 5).

\section{Discussion}

In this study, it was found that patients operated for nipple discharge were significantly older with more women above 50 years of age, compared to the non-operated group. This is consistent with other study findings [20] and might be explained by the fact that younger women want to avoid surgery until they have had their last child, since breastfeeding can be compromised after surgery. Furthermore, bloody nipple discharge was more frequent in the operated group. For the patient, blood is a more visible problem compared to clear discharge and might increase the patient's wish to get rid of the problem. Furthermore, bloody or red/brown discharge is known to be associated with an increased risk of underlying breast cancer [18], which leads the surgeon to suggest surgery in these cases.

Pathologically, duct ectasia was found in nearly half of patients, while papilloma was the cause in $39.5 \%$ of cases. In other series, papilloma is the most commonly seen cause of discharge (up to $57 \%$ of cases), while duct ectasia is described in approximately $33 \%$ of cases [10]. This difference may be explained by demographic or ethnic differences between countries, or by chance, due to low numbers in the present study.

The prevalence of CIS (8\%) and invasive cancer $(2.5 \%)$ in this study is not differing from the prevalence otherwise described in the literature (5 to $15 \%)[12,13]$.

Unlike the study by Sauter et al. [18], we found no relation between age and invasive cancer/CIS. Previous invasive cancer significantly increased the risk of invasive cancer/CIS as underlying cause of nipple discharge in both studies.

In a very recent study published in 2018 by Li GZ et al. [21], 280 patients with pathologic nipple discharge were reviewed. Using multivariable analysis, it was found that age, a palpable mass and abnormal imaging findings were associated with underlying malignancy. Duct excision was found to be reasonable in these patients. In patients without any of these three risk factors, observation rather than duct excision was suggested.

Table 4. Prevalence of cancer and carcinoma in situ (CIS) in the observation period

\begin{tabular}{|l|l|l|}
\hline & $\begin{array}{l}\text { Operation } \\
(\mathrm{n}=200)\end{array}$ & $\begin{array}{l}\text { Conservative treatment } \\
(\mathrm{n}=200)\end{array}$ \\
\hline Cancer (number (\%)) & $\begin{array}{l}1(0.5 \%) \\
(4 \text { years after surgery) }\end{array}$ & $\begin{array}{l}1(0.5 \%) \\
(2 \text { years after diagnosis })\end{array}$ \\
\hline CIS (number (\%)) & $0(0 \%)$ & $\begin{array}{l}1(0.5 \%) \\
(1 \text { year after diagnosis })\end{array}$ \\
\hline Type of discharge at inclusion & Bloody & Coloured / clear \\
\hline
\end{tabular}

Table 5. Characteristics of patients with bloody discharge (operated patients, $\mathbf{n}=200$ ) $p$ $>0.05$

\begin{tabular}{|l|l|l|}
\hline Characteristics of patients & Bloody discharge $(\mathrm{n}=142)$ & $\begin{array}{c}\text { Non-bloody discharge } \\
(\mathrm{n}=58)\end{array}$ \\
\hline Age above 50 years & $100(70.9 \%)$ & $41(70.6 \%)$ \\
\hline Previous breast cancer & $4(2.8 \%)$ & $2(3.4 \%)$ \\
\hline
\end{tabular}

In several studies and meta-analyses, bloody nipple discharge is found to be associated with underlying malignancy [22,23], while the present study did not find a significant association between bloody discharge and invasive cancer, though discharge more than once was found more frequently in the group with underlying malignancy (Table 3). This finding in the present study must be due to low numbers, since the association between bloody discharge and malignancy is wellestablished.

Kan WM et al. [24] earlier this year published results from a retrospective study on 102 patients with nipple discharge and found through multiple logistic regression that bloody discharge and an associated palpable mass were statistically significantly more common in malignancy, while age, duration of discharge, colour of discharge, palpable breast mass and abnormal sonography all were important in suggesting underlying malignancy. Kan WM et al. [24] concluded that non-bloody discharge without a palpable mass and without imaging findings infer a benign pathology in most cases.

In this study, no suspicious radiographic findings or palpable masses were described prior to surgery. This is due to the national Danish guideline regarding breast cancer treatment, which dictates that any malignancy related radiographic or clinical finding leads to enrolment in a cancer treatment program, which automatically excluded these patients from the present study on nipple discharge. Therefore, all invasive cancer/CIS found in the present study were not visible radiologically or associated with a palpable mass. Mammography alone is known to have a sensitivity of $18 \%$ in patients with pathological nipple discharge [25] which makes this a diagnostic tool of limited quality regarding intraductal pathologies. Ultrasonography identifies intraductal high risk pathology/invasive cancer in $63 \%$ of cases when performed following a negative mammography in nipple discharge patients [21]. Therefore, radiology alone is not enough to rule out underlying malignancy in this patient group.

The incidence of invasive cancer and CIS found in the follow-up period did not differ significantly between the two groups treated surgically or conservatively. Pathology was without malignant suspicion in the operated patient at time of surgery, so nothing led to increased attention in this case. Both patients had ductal invasive cancer in the follow-up period. Due to the complete national database of pathology, the incidence found is considered valid.

The present study has several limitations, which makes conclusions less generalizable. A single center study with a retrospective design and consecutive groups yields less power than a multicenter prospective randomized controlled trial would. Furthermore, the follow up time is short for a cancer study, and the homogenous study population regarding ethnicity makes generalization of the results difficult.

\section{Conclusions}

Evaluation of each patient with nipple discharge requires a thorough patient history, a thorough physical examination, and a radiologic (mammogram and ultrasonography) assessment. This study fails to identify bloody nipple discharge as a risk factor for breast cancer development, but based on the vast literature in the area, a conclusion can be made based on the overall data available. Even if all of the abovementioned examinations are inconspicuous, surgery probably should be offered patients with age above 50 years, presenting with recurrent bloody nipple. This is particularly important in case of previous breast cancer. The specific study aims to identify risk factors for cancer has 
not been fully met, but the evaluation of current treatment strategy was satisfactory. Current clinical stratification reliably identifies the patients with pathological nipple discharge requiring surgery, but over-treatment is a concern. Whether MRI will emerge as a secondline sensitive diagnostic imaging modality is to be established through future trials and studies. A step-wise approach to discriminate between physiological, benign, and malignant aetiologies is essential in order to individualize treatment and to inform patients properly, hopefully alleviating anxiety. The surgeon's clinical judgment is still important in selecting patients for surgery, and current patient selection is satisfactory. Evidence based diagnostic algorithms hopefully will occur as knowledge compiles.

\section{Acknowledgements}

Professor Jeanne Duus Johansen is thanked for valuable statistical support. All surgeons at Department of Breast Surgery, Herlev Hospital, as well as the Department of Radiology and the Department of Pathology are thanked for their contribution.

\section{References}

1. Gülay H, Bora S, Kìlìçturgay S, Hamaloğlu E, Göksel HA (1994) Management of nipple discharge. J Am Coll Surg 178: 471-474. [Crossref]

2. Falkenberry SS (2002) Nipple discharge. Obstet Gynecol Clin North Am 29: 21-29. [Crossref]

3. Murad TM, Contesso G, Mouriesse H (1982) Nipple discharge from the breast. Ann Surg 195: 259-264. [Crossref]

4. Newman HF, Klein M, Northrup JD, Ray BF, Drucker M (1983) Nipple discharge. Frequency and pathogenesis in an ambulatory population. N Y State J Med 83: 928933. [Crossref]

5. Pearlman MD, Griffin JL (2010) Benign breast disease. Obstet Gynecol 116: 747-758. [Crossref]

6. Santen RJ, Mansel R (2005) Benign breast disorders. N Engl J Med 353: 275-285. [Crossref]

7. Neville MC, McFadden TB, Forsyth I (2002) Hormonal regulation of mammary differentiation and milk secretion. J Mammary Gland Biol Neoplasia 7: 49-66. [Crossref]

8. Rodden AM (2009) Common breast concerns. Prim Care 36: 103-113, viii. [Crossref]

9. Pruthi S (2001) Detection and evaluation of a palpable breast mass. Mayo Clin Proc 76: 641-647. [Crossref]
10. Vargas HI, Vargas MP, Eldrageely K, Gonzalez KD, Khalkhali I (2006) Outcomes of clinical and surgical assessment of women with pathological nipple discharge. Am Surg 72: 124-128. [Crossref]

11. Sydnor MK, Wilson JD, Hijaz TA, Massey HD, Shaw de Paredes ES (2007) Underestimation of the presence of breast carcinoma in papillary lesions initially diagnosed at core-needle biopsy. Radiology 242: 58-62. [Crossref]

12. Jardines L (1996) Management of nipple discharge. Am Surg 62: 119-122. [Crossref]

13. Dolan RT, Butler JS, Kell MR, Gorey TF, Stokes MA (2010) Nipple discharge and the efficacy of duct cytology in evaluating breast cancer risk. Surgeon 8: 252-258. [Crossref]

14. Cabioglu N, Hunt KK, Singletary SE, Stephens TW, Marcy S, et al. (2003) Surgical decision making and factors determining a diagnosis of breast carcinoma in women presenting with nipple discharge. J Am Coll Surg 196: 354-364. [Crossref]

15. King TA, Carter KM, Bolton JS, Fuhrman GM (2000) A simple approach to nipple discharge. Am Surg 66: 960-965. [Crossref]

16. Dawes LG, Bowen C, Venta LA, Morrow M (1998) Ductography for nipple discharge: no replacement for ductal excision. Surgery 124: 685-691. [Crossref]

17. Dinkel HP, Gassel AM, Muller T, Lourens S, Rominger M, et al. (2001) Galactography and exfoliative cytology in women with abnormal nipple discharge. Obstet Gynecol 97: 625-629. [Crossref]

18. Tjalma WA, Verslegers IO (2004) Suspicious nipple discharge and breast magnetic resonance imaging. Breast $J$ 10:65-66. [Crossref]

19. Flyger HL, Bjerrum PJ, West-Nielsen E, Bødker AW, Meyhoff HH (1996) Usefulness of urine dipsticks in the diagnosis of microscopic hematuria. Ugeskr Laeger 158: 67596762. [Crossref]

20. Sauter ER, Winn JN, Dale PS, Wagner-Mann C (2006) Nipple aspirate fluid color is associated with breast cancer. Cancer Detect Prev 30: 322-328. [Crossref]

21. Li GZ, Wong SM, Lester S, Nakhlis F (2018) Evaluating the risk of underlying malignancy in patients with pathologic nipple discharge. Breast $J 24$ : 624-627. [Crossref]

22. Morrogh M, Park A, Elkin EB, King TA (2010) Lessons learned from 416 cases of nipple discharge of the breast. Am J Surg 200: 73-80. [Crossref]

23. Chen L, Zhou WB, Zhao Y, Liu XA, Ding Q, et al. (2012) Bloody nipple discharge is a predictor of breast cancer risk: a meta-analysis. Breast Cancer Res Treat 132: 9-14. [Crossref]

24. Kan WM, Chen C, Kwong A (2018) Implications of nipple discharge in Hong Kong Chinese women. Hong Kong Med J 24: 18-24. [Crossref]

25. Morrogh M, Morris EA, Liberman L, Borgen PI, King TA (2007) The predictive value of ductography and magnetic resonance imaging in the management of nipple discharge. Ann Surg Oncol 14: 3369-3377. [Crossref]

Copyright: $₫ 2018$ Røpcke DM. This is an open-access article distributed under the terms of the Creative Commons Attribution License, which permits unrestricted use, distribution, and reproduction in any medium, provided the original author and source are credited. 